\title{
Derivation of population distribution for vulnerability assessment in flood-prone German cities using multisensoral remote sensing data
}

\author{
Michael Wurm* ${ }^{\text {a }, ~}$, Hannes Taubenböck ${ }^{\mathrm{a}, \mathrm{b}}$, Susanne Krings ${ }^{\mathrm{c}}$, Jörn Birkmann ${ }^{\mathrm{c}}$, Achim Roth ${ }^{\mathrm{a}}$, Stefan \\ Dech $^{\mathrm{a}, \mathrm{b}}$ \\ ${ }^{\mathrm{a}}$ German Remote Sensing Data Center (DFD), German Aerospace Center (DLR), Oberpfaffenhofen, \\ 82234 Wessling, Germany \\ bulius-Maximilians-Universität Würzburg, Department of Geography, Am Hubland, \\ 97074 Würzburg, Germany \\ ${ }^{c}$ United Nations University, Institute for Environment and Human Security (EHS), UN Campus, \\ Hermann-Ehlers-Str.10, 53113 Bonn, Germany
}

\begin{abstract}
Against the background of massive urban development, area-wide and up-to-date spatial information is in demand. However, for many reasons this detailed information on the entire urban area is often not available or just not valid anymore. In the event of a natural hazard - e.g. a river flood - it is a crucial piece of information for relief units to have knowledge about the quantity and the distribution of the affected population. In this paper we demonstrate the abilities of remotely sensed data towards vulnerability assessment or disaster management in case of such an event. By means of very high resolution optical satellite imagery and surface information derived by airborne laser scanning, we generate a precise, three-dimensional representation of the landcover and the urban morphology. An automatic, object-oriented approach detects single buildings and derives morphological information - e.g. building size, height and shape - for a further classification of each building into various building types. Subsequently, a top-down approach is applied to distribute the total population of the city or the district on each individual building. In combination with information of potentially affected areas, the methodology is applied on two German cities to estimate potentially affected population with a high level of accuracy.
\end{abstract}

Keywords: Vulnerability assessment, population estimation, river flood, VHR optical satellite data, ALS

\section{INTRODUCTION}

Within the past two centuries urbanization processes have led to a concentration of population in urban settlements throughout the world. In the year 2008, the proportion of worldwide urban population has reached 50 per cent while in industrialized countries such as Germany 73.5 per cent of the population live in cities (United Nations, 2008). Compared to the size of urbanized areas in Germany - around 8 per cent of the total area in 2007 (Federal Statistical Office Germany, 2009) - it becomes obvious that cities are characterized by a high concentration of inhabitants. However, it is the task of the Federal Statistical Office to establish and regularly update official records about the population size in Germany on the municipal level (Federal Ministry of Justice, 2009). Depending on the size and administrative structure, each municipality may keep their own records; subdivided into districts or neighborhoods, but location-based information of the population on a small scale is often lacking or not available - due to data protection - for nonmunicipal organizations. But especially for cities prone to natural hazards - e.g. river floods, tsunamis, earth quakes and others - it is of essential importance to have access to information on the spatial distribution and quantification of the local population. In the event of such a hazard, relief units need to be able to quickly respond to the questions: 'How many people are affected?' and 'Where are affected people?'. Against this background, this study focuses on the addressed questions and the contribution of remote sensing and GIS (Geographic Information System) technology to provide knowledge about the population distribution in flood-prone German cities for the purpose of vulnerability assessment.

*michael.wurm@dlr.de; phone +49 (0)8153 28-2154; fax+49 (0)8153 28-1445; http://www.dlr.de/caf/desktopdefault.aspx/tabid-4937/8208 read-13549/

Remote Sensing for Environmental Monitoring, GIS Applications, and Geology IX, edited by Ulrich Michel, Daniel L. Civco, Proc. of SPIE Vol. 7478, 74781K · C 2009 SPIE · CCC code: 0277-786X/09/\$18 · doi: 10.1117/12.830318 
To this end, spaceborne as well as airborne remote sensing data is utilized for the derivation of highly detailed information on the physical structure of a city as basis for the assessment of the population distribution. A modular, object-oriented and transferable framework was developed to retrieve knowledge about the landcover and the urban morphology of the study area by means of very high resolution (VHR) optical satellite imagery (e.g. IKONOS) and a DSM (digital surface model) derived by airborne laserscanning. The last generation of VHR satellite sensors (e.g. IKONOS, Quickbird, GeoEye-1, WorldView-1) provides image data with a geometrical resolution higher than 1 meter which allows spatially and thematically detailed analysis over urban areas on house or block level (Maktav, Erbek \& Jürgens, 2005). However, new challenges in image analysis have come up with the introduction of these high resolution image data (Donnay et al., 2001) and new, object-oriented classification concepts have since been developed (Blaschke \& Strobl, 2001).

The essential prerequisite for object-oriented image analysis is the structuring of the single, isolated picture elements into more or less homogeneous areas. Various methods for image segmentation have been developed and presented (Baatz \& Schäpe, 2000, Neubert, Herold \& Meinel, 2006 and Neubert \& Herold, 2008). Generally, the analysis of twodimensional image data is limited to two-dimensional results, albeit concepts for the estimation of building heights through shadow lengths have been applied (Taubenböck, Roth \& Dech, 2007). With the wide application of airborne laserscanning data (ALS) in urban areas, various methods for building extraction have been sought. Based on the DSM, a generic model for the detection and reconstruction of buildings has been developed (Weidner, 1996) as well as an automated segmentation method including reconstruction of various roof types was presented (Brenner, 2000) while other methods utilize directly observed point clouds generated by LiDAR (Rottensteiner \& Briese, 2003) or the joint analysis of both, LiDAR and aerial imagery (Rottensteiner et al., 2004).

A various number of concepts for linking remote sensing data and socioeconomic or demographic data have been discussed. Sutton et al. (1997) correlated nighttime satellite imagery with a geometrical resolution of 1-by-1 km with population density for the entire continental United States of America and a correlation of areal census data with residential densities by means of Landsat TM data was done by Chen (2002). However, Jensen (1999) suggests the identification of individual dwelling units with very high spatial resolution imagery for a high correlation coefficient with census data. Liu et al. (2006) found very sophisticated methods for linking population density to image texture by utilizing the spatial metrics method. A further step in mapping population distribution was done by Kressler \& Steinnocher (2008) including height information derived by ALS in combination with IKONOS-2 imagery. Taubenböck et al. (2009) went one step further correlating physical urban structures with socio-economic parameters of the people residing there. The presented study shows an approach for the spatial disaggregation of census data on the basis of buildings derived by a joint analysis of very high resolution optical satellite imagery and surface information from ALS data for the purpose of vulnerability assessment in flood-prone German cities like Cologne and Dresden.

\section{STUDY AREAS AND DATA SETS}

River floods are a natural phenomenon and emerge periodically in non-regulated rivers without harming the natural environment - they even have an important ecological function. However, human settlements and the development of large urban areas made it a necessity to reduce flood-related hazards on humans or infrastructure by river regulations. But flood control measures raise exaggerated expectation towards security against river floods and the absence of a relevant flooding for some decades in a city may reduce the risk awareness (WWF, 2007). The last peak level of the river Elbe in Dresden before the flood in 2002 happened in 1845 (Figure 1). Census data for the year 1852 show that the city around this time had a total population of just above 100000 (Landeshauptstadt Dresden). It comes as no surprise that the citizens of the city of Dresden, which saw a massive growth since this last severe event (Dresden today is the capital of the Free State of Saxony and with more than 500000 inhabitants $13^{\text {th }}$ largest city in Germany), were completely surprised by the flood event in 2002. On the other hand, Cologne has a long history of continuously repeating river floods throughout the centuries. Situated at the Rhine in the West of Germany, Cologne is Germany's fourth largest city and bears the burden of being Europe's most flood prone city over 1 million inhabitants. Within the past decades, Cologne has experienced flood-related damages of several millions of euros (Stadt Köln, 1996). In total - for the entire affected area - the river floods of the Rhine in 1993 and 1995 caused damages of $4 \mathrm{bn} €$ and the Elbe flood in 2002 destroyed property to an extent of $11 \mathrm{bn} €$. As these two cities have been affected by major flood events they hold an excellent data basis that is necessary for evaluation processes, both cities serve as very suitable examples to develop and assess the methods explored in this study. 


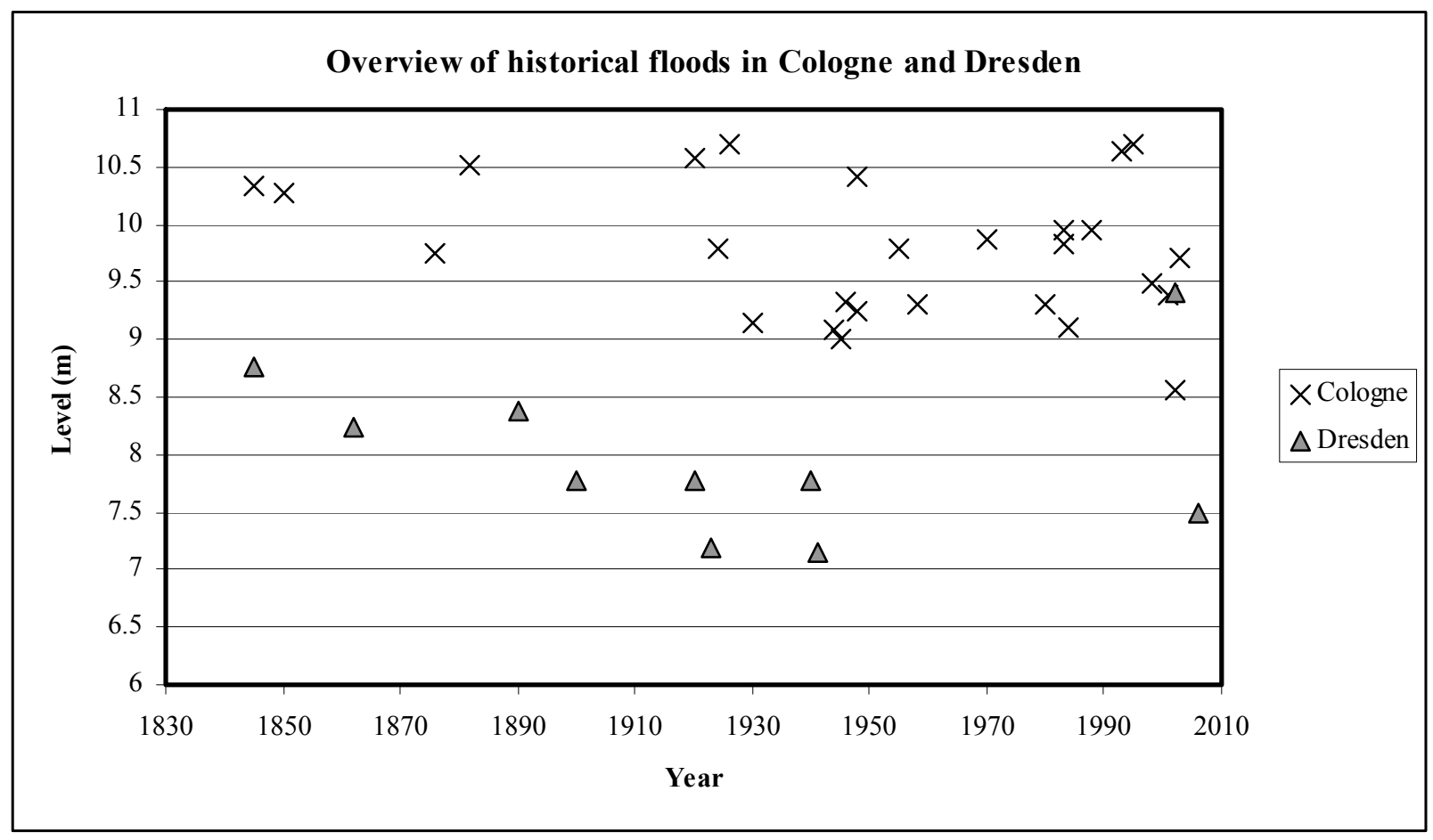

Figure 1. Overview of historical river floods in Cologne and Dresden between the years 1845 and 2006 (Source: www.dresden-online.de, Stadt Köln, 1996 and Stadtentwässerungsbetriebe Köln, AöR).

For this study we utilized VHR optical satellite imagery (IKONOS-2) with a ground resolution of $1 \mathrm{~m}$ panchromatic and $4 \mathrm{~m}$ multispectral. By means of image fusion, the high geometrical resolution of the panchromatic band is combined with the four spectral bands of the blue, green, red and near infrared (NIR) band using pansharpening. Such a high level of detail is required for the identification of features - like single buildings or streets - and the remaining land cover in the small structured urban landscape. However, the coverage of a single IKONOS-2-scene is limited to $11 \mathrm{~km} * 11 \mathrm{~km}$. Hence, for a full coverage of a city several scenes have to be acquired. The digital surface model of the city is derived by ALS, an active remote sensing system. It measures the running time of a laser beam between the sensor, the reflecting surface on ground - and back. By means of GPS (Global Positioning System) and INS (Intertial Navigations System) the absolute position of the reflecting object - in $\mathrm{x}, \mathrm{y}$ and z-direction - can be distinguished. The geometrical resolution may vary depending on the density of the laser beams between a few centimeters and a few meters (Hofmann, 2005). ALS is utilized for the derivation of DSM or digital terrain models (DTM) in various applications and environments (e.g. urban, forest, glaciology). An overview of the utilized data sets is shown in Table 1 and the location of the study areas in Germany, together with their urban footprints is presented in Figure 2.

Table 1. Characteristics of utilized remote sensing data sets.

\begin{tabular}{|l|l|l|l|l|}
\hline \multirow{2}{*}{ LiDAR } & \multicolumn{2}{|c|}{ Cologne } & \multicolumn{2}{c|}{ Dresden } \\
\cline { 2 - 5 } & Date & Resolution & Date & Resolution \\
\hline IKONOS & 2007 & $1 \mathrm{~m}$ & 2001 & $1 \mathrm{~m}$ \\
(no. of scenes) & $05 / 2007$ & $1 \mathrm{~m}($ pan.) & $08 / 2007$ & $1 \mathrm{~m}(\mathrm{pan})$. \\
& $07 / 2007(5)$ & $4 \mathrm{~m}(\mathrm{~ms})$. & $(3)$ & $4 \mathrm{~m}(\mathrm{~ms})$. \\
\hline
\end{tabular}




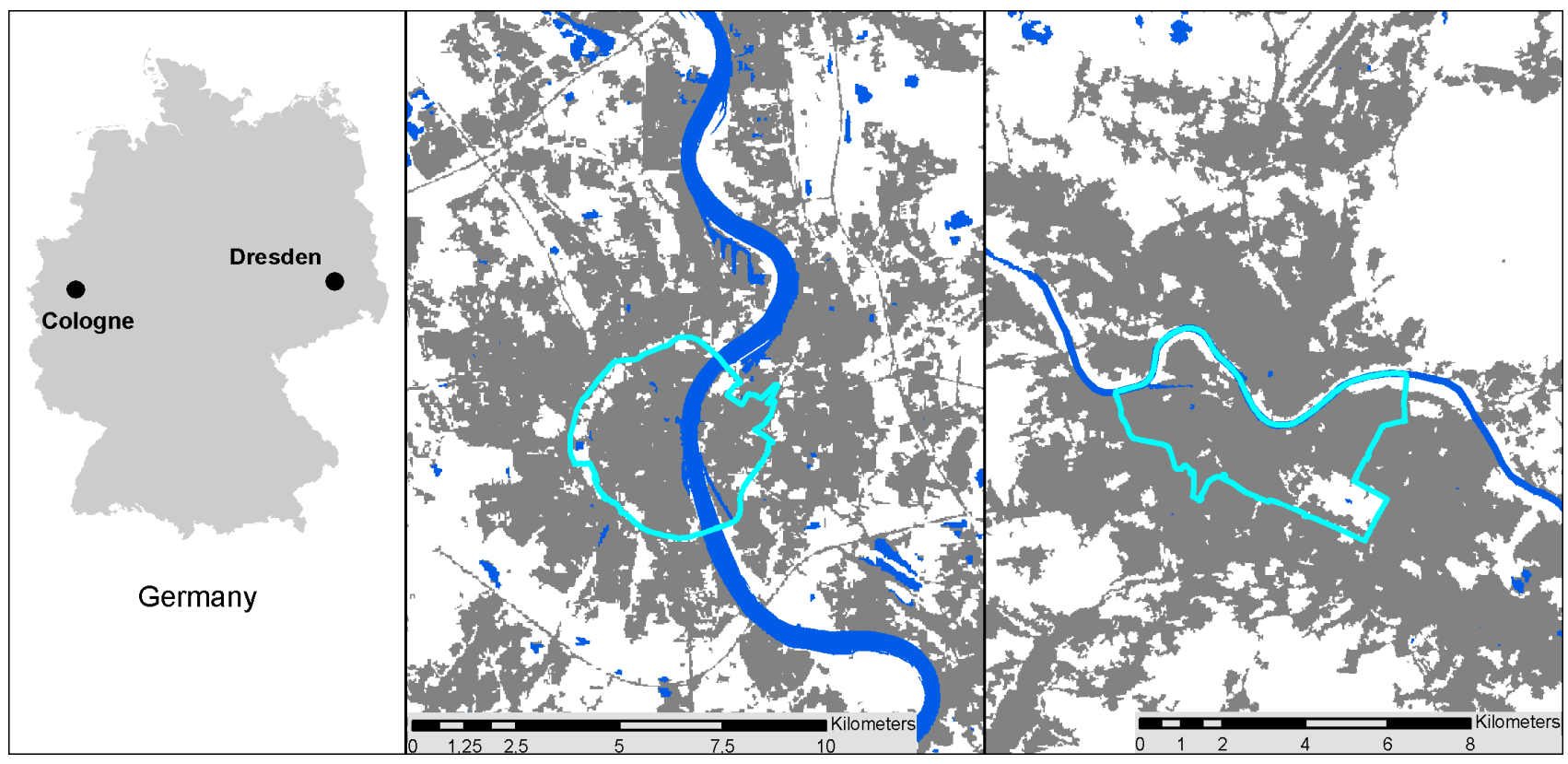

Figure 2. Location of the cities Cologne and Dresden in Germany and their urban footprint derived by Landsat

Enhanced Thematic Mapper Plus (2000).

The population data of the cities serve as external input for spatial disaggregation. These data sets are available on various statistical-administrative levels for Dec. 31 2007: (1) the city level, (2) borough (3) city districts and (4) neighborhoods. For the analysis we utilized data on district level for both cities, as the units are of similar spatial dimensions.

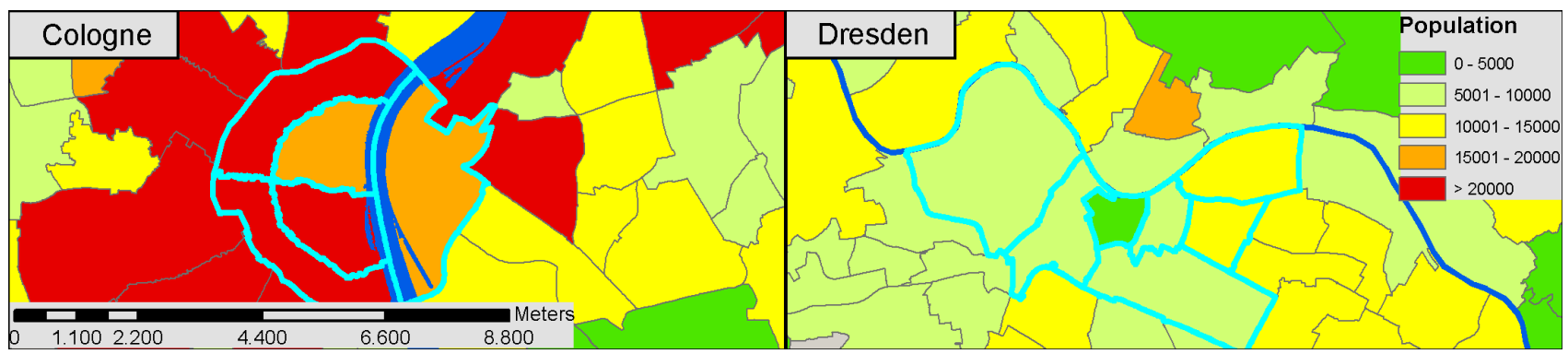

Figure 3. Magnification of the city center of Cologne and Dresden and the selected districts with total population (legend valid for both images).

\section{METHODOLOGY}

For the retrieval of highly detailed population estimation on local level by means of remote sensing data, the smallest spatial unit for the spatial disaggregation of the population data has to be extracted first. In the following, the methodology for the detailed extraction of single buildings and building types is presented as well as the derivation of the population distribution.

\subsection{Building extraction and landcover classification}

An object-oriented and transferable workflow was developed to extract a high resolution landcover classification and a proper description of individual buildings in terms of size and shape. The methodology is implemented into a fixed, modular-based framework and can be processed independently from each other, but best results are achieved by following the presented workflow: Each of the two modules is structured in the same way: (a) image segmentation and (b) object-oriented classification. The first module - Module I-DSM - starts with a $5 * 5$ median filter to remove artifacts and to smooth the boundaries. Further, a basic segmentation level is created either by a rough multiresolution 
segmentation or by importing external block boundaries provided by ATKIS (Official Topographic Cartographic Information System). Based on these spatial units, various statistical parameters are calculated for each object and a block-by-block sub-segmentation is performed to extract outlines for single buildings (Figure 4). Segmentation in this way has been proven significantly faster performance than segmentation of the entire study area at once.

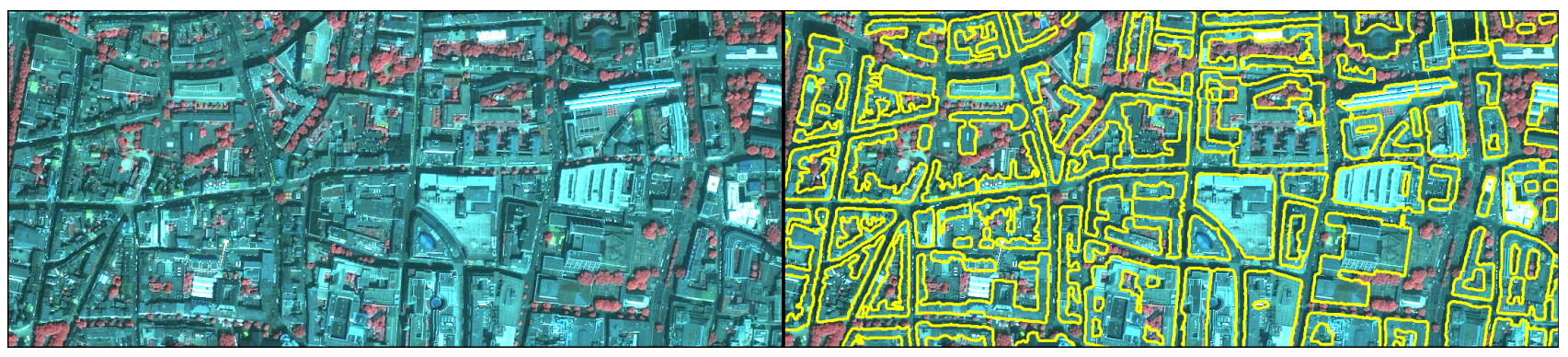

Figure 4. Result of building extraction via image segmentation for a subset of Cologne (right) overlaid on IKONOS false-color composite (left, 4/3/2).

To integrate the third dimension into the population estimation, the height for each building is calculated by the difference of its mean absolute height and the mean elevation for the ground of its surrounding block. An estimated average building floor height was applied to express the building height in number of floors and therefore to create an exact representation of the building size for the assessment of population. Building size - area and floors - as well as building shape is utilized in the final step to classify various types of buildings. A fuzzy-logic classification is applied to derive - so far - five different building types: 'detached/semi-detached buildings', 'terraced', 'building blocks', 'highrise buildings' and 'non-residential/industrial'.

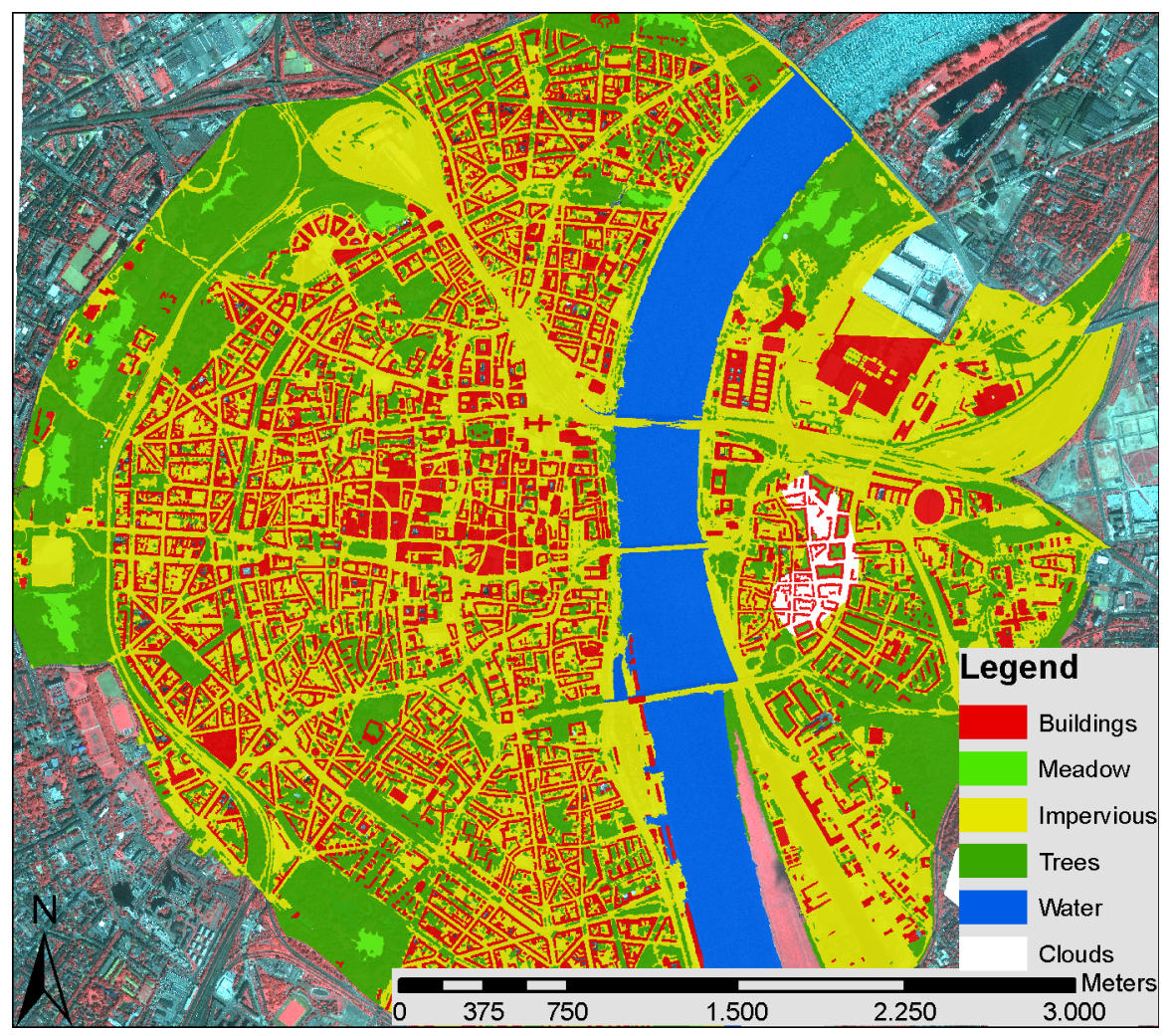

Figure 5. Result of object-based classification of five different landcover types for Cologne (overlaid on IKONOS false-color composite 4/3/2). 
The workflow for the second module - Module II VHR-opt - is structured in the same way as the first module and also designed to be applicable on various very high resolution sensors (Taubenböck \& Roth, 2007). The hierarchical image segmentation optimization procedure starts with a very low scale parameter for the first segmentation level and splits the image into rather small objects. Through the following optimization steps spectrally similar objects are merged together on the next segmentation level which was created with an increased scale parameter. This procedure is repeated until very small and very large objects are represented in the same level (Esch et al., 2008). The classification step then assigns each object by a fuzzy-approach to one of the landcover classes starting with the coarsest segmentation level until all objects in the finest segmentation level are classified. A more detailed description of the workflow was presented by Wurm et al. (2009). Figure 5 shows the classification result for Cologne already giving a visual impression of the physical urban structure.

\subsection{Spatial disaggregation and estimation of affected population}

After building outlines as well as building heights and building types are extracted from remotely sensed imagery, the population of the investigated region can be assessed. Hence, for a detailed estimation the total population of the city district is allocated over the area on the basis of single buildings by means of spatial disaggregation (Steinnocher et al., 2005, Aubrecht et al. 2009).

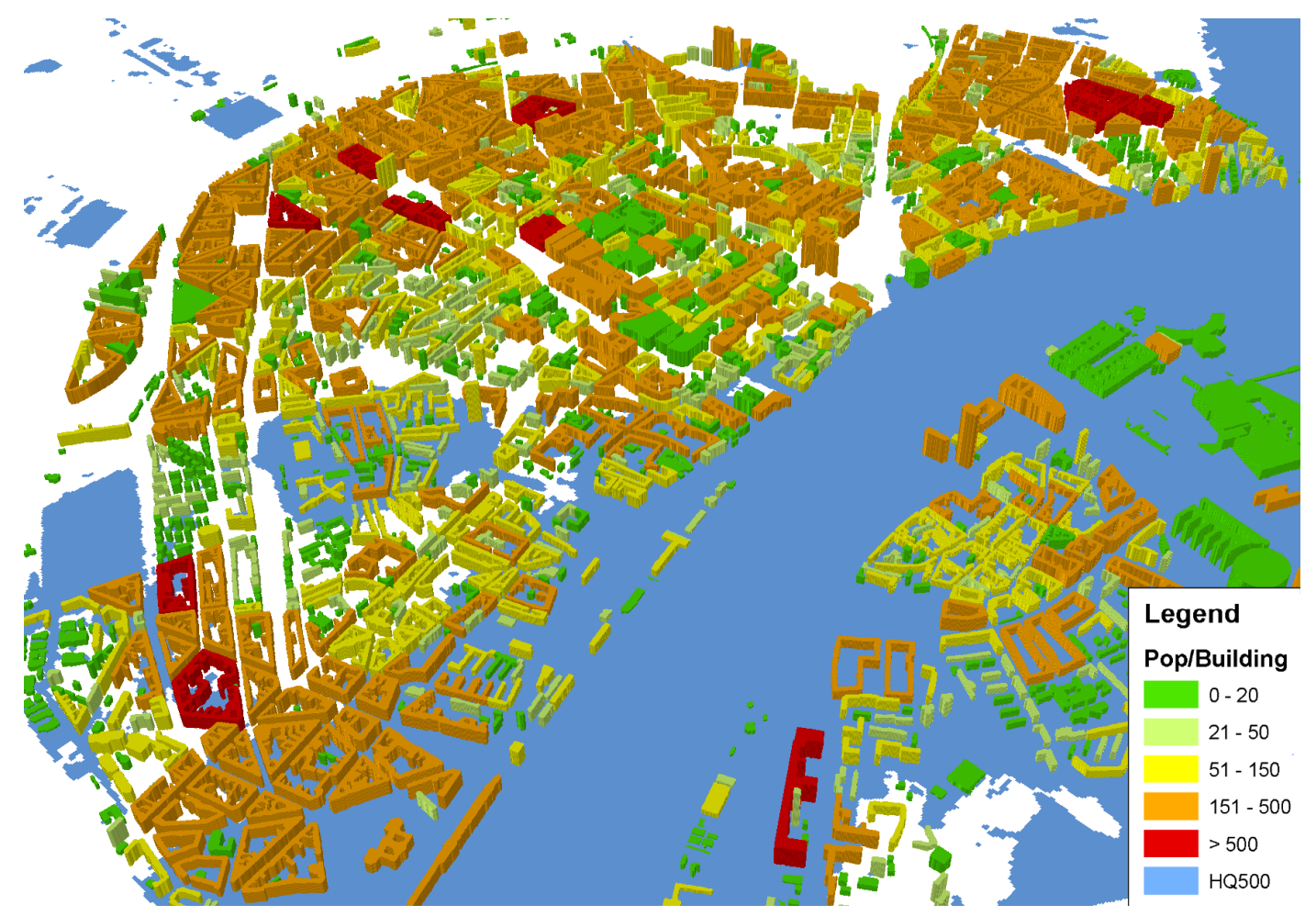

Figure 6. Estimated population for each building for the city center of Cologne.

The estimation is based on several assumptions: (1) Total population is distributed equally over the entire region based on the extracted buildings. (2) People only dwell in residential buildings. Thus, only buildings which were classified as one of the residential classes are taken into account for further processing. (3) Local disaggregation of population is dependent on the interrelationship of living space and population.

Based on these assumptions, the population is distributed following equation (1):

$$
P h=\frac{L s_{h}}{L s_{t}} \cdot P_{t}
$$


where $P h$ is the population per house, $L s_{h}$ the living space per house, $L s_{t}$ the total living space and $P t$ the total population. The living space is defined as the product between the area $A_{h}$ and the height in floors $h_{h}$ for each building and $v$ being the apartment vacancy proportion (if available).

$$
L s_{h}=\left(A_{h} \cdot h_{h}\right) \cdot(1-v)
$$

The total living space $L s_{t}$ is calculated using the following equation (3):

$$
L s_{t}=\sum_{h=1}^{1} L s_{h}
$$

After the total population of the city district was spatially disaggregated over the single buildings in the study area, the potentially affected population can be assessed. This is done by spatial overlay of an exemplary flood scenario - in our case we used an extreme flood event (HQ500) - with the classification result in a GIS. The buildings within the boundary of the HQ500 - which is the estimated, statistical maximum discharge of an event every 500 years - comprise the potentially affected population (Figure 6).

\section{RESULTS AND DISCUSSION}

\subsection{Building extraction and landcover classification}

The accuracies of the applied methodologies are assessed individually for the results. For the assessment of the number of floors for each building, an official digital building model was supplied by the cities Cologne and Dresden. The digital building model holds the relative building height as well as the number of floors for each building. Table 2 shows the results of comparing both data sets with the official number of floors. The deviation of floors is expressed based on the classification result for all buildings holding the same number of floors. Thus, 49.45 per cent of the buildings holding two floors in Cologne were classified correctly and 46.15 per cent were underestimated by one floor. As the number of floors for each building was estimated by a mean floor height, variations in accuracies depending on the building height appear. For both data sets it is obvious that underestimation of the number of floors rises with rising number of floors. Especially within the city center, where old building structures - with a higher mean floor height - dominate, a significant deviation can be observed. However, a mean accuracy for buildings with a maximum deviation of \pm 1 floor shows relatively good results for the height estimation. Figure 7 visualizes the derived building levels for the city centers of Cologne and Dresden.

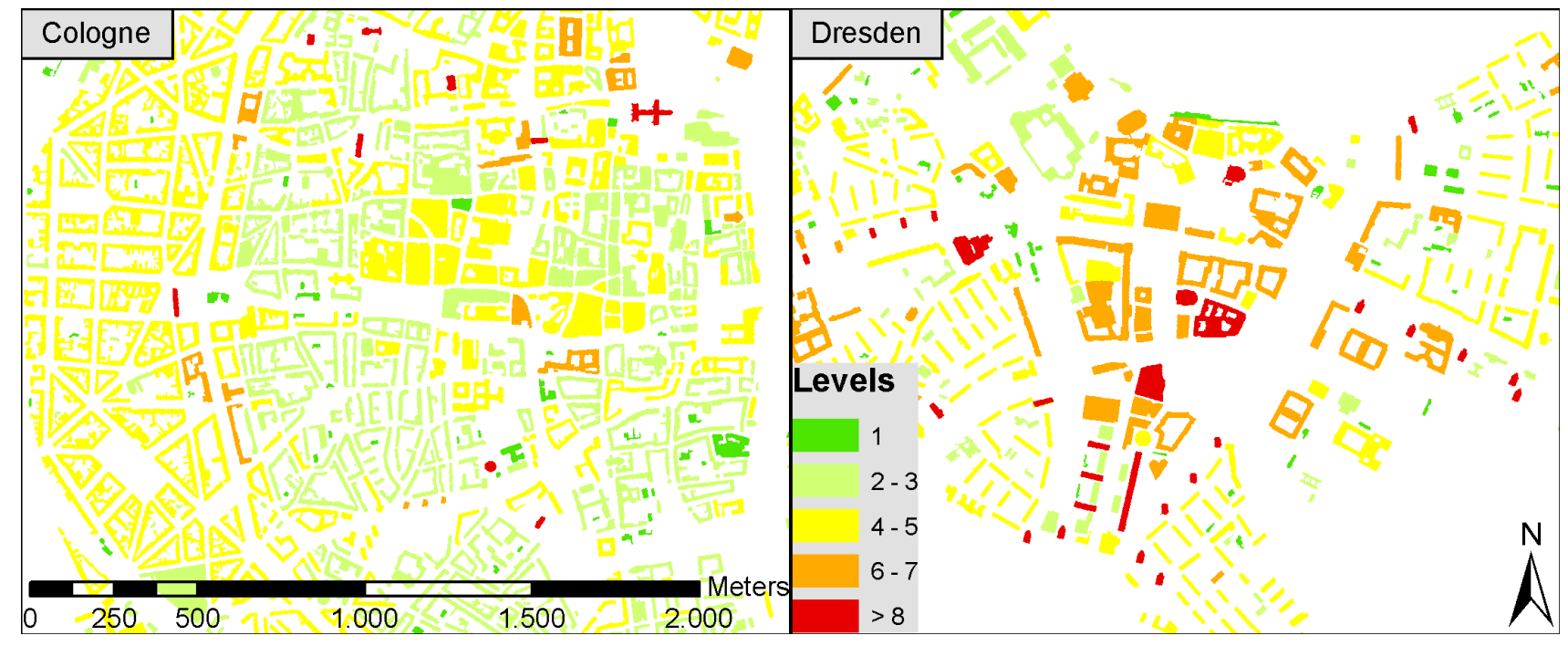

Figure 7. Building levels derived by LiDAR-data for the city centers of Cologne and Dresden. 
Table 2. Accuracy assessment of building floor estimation for the study areas in Cologne and Dresden.

\begin{tabular}{|c|c|c|c|c|c|}
\hline & \multicolumn{5}{|c|}{ Deviation of floors } \\
\hline Cologne & $\leq-2$ & -1 & $\mathbf{0}$ & +1 & $\geq+2$ \\
\hline 2 floors & - & 46.15 & 49.45 & 2.20 & 2.20 \\
\hline 3 floors & 4.11 & 45.21 & 44.52 & 6.16 & - \\
\hline 4 floors & 7.86 & 48.21 & 37.86 & 5.71 & 0.36 \\
\hline 5 floors & 21.21 & 55.68 & 20.45 & 2.65 & - \\
\hline$\geq 6$ floors & 41.41 & 23.44 & 35.16 & - & - \\
\hline \multirow{2}{*}{ mean } & \multirow{2}{*}{14.92} & 43.74 & 37.49 & 3.34 & \multirow{2}{*}{0.51} \\
\hline & & \multicolumn{3}{|c|}{84.57} & \\
\hline & \multicolumn{5}{|c|}{ Deviation of floors } \\
\hline Dresden & $\leq-2$ & -1 & $\mathbf{0}$ & +1 & $\geq+2$ \\
\hline 2 floors & - & - & 85.11 & 10.64 & 4.26 \\
\hline 3 floors & - & 66.40 & 28.80 & 4.80 & - \\
\hline 4 floors & 27.14 & 52.14 & 17.14 & 2.86 & 0.71 \\
\hline 5 floors & 24.19 & 38.31 & 35.89 & 1.61 & - \\
\hline$\geq 6$ floors & 20.58 & 52.67 & 26.75 & - & - \\
\hline \multirow{2}{*}{ mean } & \multirow{2}{*}{14.38} & 41.90 & 38.74 & 3.98 & \multirow{2}{*}{0.99} \\
\hline & & & 84.62 & & \\
\hline
\end{tabular}

The accuracy of the landcover classification was assessed by visual inspection of 100 randomized sample points for each class. A very common way of representing the results is with an error matrix (or confusion matrix) where the user accuracy and the producer accuracy as well as the total weighted accuracy are displayed. The approach for landcover classification with VHR optical imagery shows very satisfying results for both study areas and proves to be transferable between various study areas (Table 3 ).

Table 3. Accuracy assessment of landcover classification for the study areas in Cologne and Dresden.

\begin{tabular}{|c|c|c|c|c|}
\hline & \multicolumn{2}{|c|}{ Cologne } & \multicolumn{2}{c|}{ Dresden } \\
\hline LC class & $\begin{array}{c}\text { User accuracy } \\
\%\end{array}$ & $\begin{array}{c}\text { Producer } \\
\text { accuracy \% }\end{array}$ & $\begin{array}{c}\text { User accuracy } \\
\%\end{array}$ & $\begin{array}{c}\text { Producer } \\
\text { accuracy \% }\end{array}$ \\
\hline Buildings & 90.83 & 98.00 & 95.92 & 94.00 \\
Impervious Surface & 96.70 & 88.00 & 92.39 & 85.00 \\
Lawn / Meadow & 81.25 & 91.00 & 76.61 & 95.00 \\
Tree / Woodland & 88.76 & 79.00 & 92.21 & 71.00 \\
Water surface & 98.99 & 98.00 & 91.74 & 100.00 \\
\hline Overall accuracy \% & \multicolumn{3}{|c|}{$\mathbf{9 1 . 1 5}$} & \multicolumn{3}{|c|}{} \\
\hline
\end{tabular}




\subsection{Spatial disaggregation and estimation of affected population}

The accuracies of the spatial disaggregation - which was performed on the basis of city districts - were assessed on the level of neighborhoods for the city center of Cologne. Thus, official population data on neighbourhood level was compared to the estimated population and the deviation is expressed as observation error $(\varepsilon)$ for each neighborhood. Table 4 shows that the estimation of the population on neighbourhood level deviates on average by 20.48 per cent.

Table 4. Accuracy assessment of spatial disaggregation and estimation of affected population in Cologne.

\begin{tabular}{|c|c|c|c|c|c|c|}
\hline Neighborhood name & Total Pop. & Est. Pop. & Obs. \& & Aff. Pop. & Est. Aff. & Obs. \& \\
\hline Kapitol-Viertel & 1632 & 2233 & 36.83 & 161 & 102 & -36.65 \\
\hline Mauritius-Viertel & 4386 & 4491 & 2.39 & 0 & 0 & 0 \\
\hline Cäcilien-Viertel & 3196 & 4101 & 28.32 & 0 & 0 & 0 \\
\hline Pantaleons-Viertel & 4872 & 4638 & -4.80 & 3169 & 2885 & -8.96 \\
\hline Georgs-Viertel & 2478 & 4048 & 63.36 & 2292 & 3320 & 44.85 \\
\hline Severins-Viertel & 10972 & 8112 & -26.07 & 5239 & 4487 & -14.35 \\
\hline Südstadt & 14820 & 14541 & -1.88 & 8114 & 8633 & 6.40 \\
\hline Volksgarten-Viertel & 4949 & 5625 & 13.66 & 248 & 273 & 10.08 \\
\hline Studenten-Viertel & 2666 & 1502 & -43.66 & 0 & 0 & 0 \\
\hline Südbahnhof-Viertel & 2527 & 1787 & -29.28 & 0 & 0 & 0 \\
\hline Komponisten-Viertel & 7298 & 8339 & 14.26 & 3 & 0 & - \\
\hline Rathenau-Viertel & 3836 & 3594 & -6.31 & 13 & 0 & - \\
\hline Gewerbegebiet Südstadt & 1813 & 2573 & 41.92 & 745 & 645 & -13.42 \\
\hline Kuniberts-Viertel & 3774 & 2803 & -25.73 & 900 & 1491 & 65.67 \\
\hline Eigelstein-Viertel & 2646 & 599 & -77.36 & 0 & 0 & 0 \\
\hline Gereons-Viertel & 2885 & 2349 & -18.58 & 21 & 0 & - \\
\hline Neumarkt-Viertel & 1697 & 3408 & 100.82 & 0 & 0 & 0 \\
\hline City & 959 & 2810 & 193.01 & 0 & 0 & 0 \\
\hline Martins-Viertel & 1426 & 1276 & -10.52 & 1081 & 1015 & -6.11 \\
\hline Ursula-Viertel & 2051 & 815 & -60.26 & 0 & 0 & 0 \\
\hline Andreas-Viertel & 918 & 2846 & 210.02 & 0 & 0 & 0 \\
\hline Apostel-Viertel & 2164 & 1615 & -25.37 & 44 & 68 & 54.55 \\
\hline Belgisches Viertel & 6620 & 5217 & -21.19 & 137 & 0 & - \\
\hline Stadtgarten-Viertel & 2311 & 3642 & 57.59 & 144 & 257 & 78.47 \\
\hline Agnes-Viertel & 13555 & 8946 & -34.00 & 0 & 0 & 0 \\
\hline Media-Park & 2253 & 4250 & 88.64 & 48 & 1075 & 2139.58 \\
\hline Gerichts-Viertel & 2435 & 3424 & 40.62 & 1271 & 2061 & 62.16 \\
\hline Villen-Viertel & 1000 & 2042 & 104.20 & 271 & 283 & 4.43 \\
\hline Colonius & 678 & 1326 & 95.58 & 0 & 0 & 0 \\
\hline Deutz & 7287 & 5930 & -18.62 & 7091 & 5930 & -16.37 \\
\hline Germanen-Viertel & 3411 & 2317 & -32.07 & 3348 & 2317 & -30.79 \\
\hline Hafen-Viertel & 2440 & 3769 & 54.47 & 2060 & 3088 & 49.90 \\
\hline Fachhochschule Deutz & 1714 & 1735 & 1.23 & 1023 & 1735 & 69.60 \\
\hline Köln-Arena & 820 & 699 & -14.76 & 760 & 699 & -8.03 \\
\hline Mean & 3779.09 & 3747.12 & 20.48 & 1123.03 & 1187.18 & $10.74^{*}$ \\
\hline
\end{tabular}

*Without observation error for neighborhood 'Media-Park'. 
However, very high errors occur in the neighborhoods "City" and "Andreas-Viertel", which are located in the downtown area which is also the business center with many stores and therefore characterized by a very low population density. The potentially affected population by an extreme river flood was assessed with official reference data on the level of neighborhoods. This reference was created by the city of Cologne on the basis of addresses and aggregated to the neighborhood level. The estimation of potentially affected population for the city center of Cologne shows quite good results and the variation and dimension of the population shows a lot of similarities. The mean observed error shows only 10.74 per cent deviation - without the neighborhood 'Media-Park' which is home to more than 250 business companies. The same methodology for estimation of affected population was applied on the center of the city of Dresden. However, for Dresden reference data was not available. Thus, the assessment of population data using remote sensing information does not allow for cadastral accuracies, but enables the consequent assessment of the correct dimension. For both cities, the potentially affected population is visualized on neighborhood level in Figure 8.

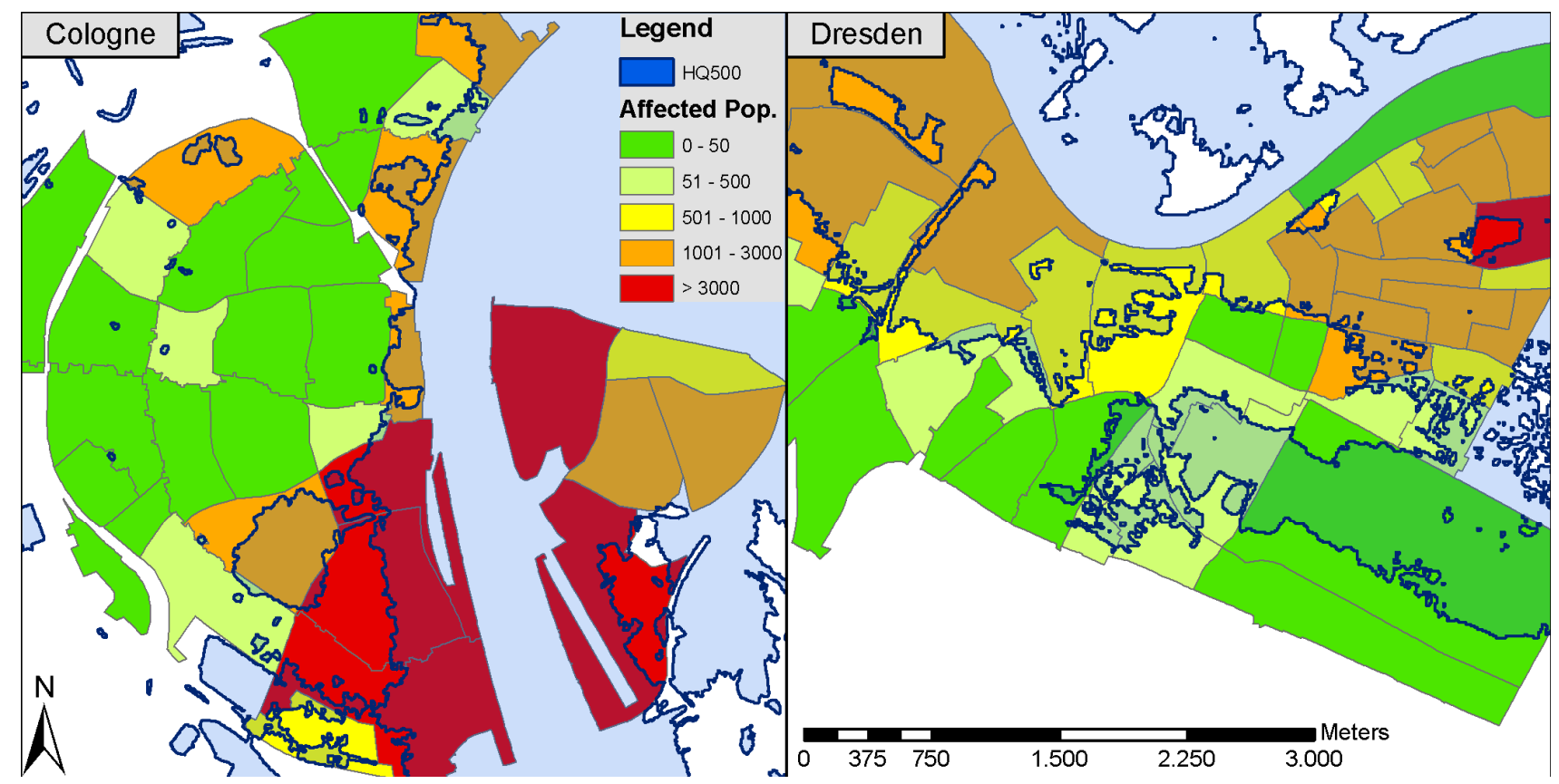

Figure 8. Estimated affected population on neighborhood level for Cologne and Dresden.

\section{CONCLUSION AND OUTLOOK}

This study has demonstrated the powerful contribution of remote sensing for vulnerability analysis in flood-prone urban areas. By means of object-oriented analysis of VHR optical satellite imagery and digital surface model derived by ALS a three-dimensional city model has been generated for the purpose of population estimation. On the basis of single buildings, population data on city district level was spatially disaggregated over the study area to retrieve population distribution on a very large scale. In the case of a river flood, potentially affected population can be estimated and information for relief units can be provided. The methodology has shown good results in terms of the right dimension of population. The initially formulated question: 'How many people are affected?' and 'Where are affected people?' can be answered by applying the presented methodology. However, future research will focus on a more precise classification of building types in terms of usage of the building as especially neighborhoods with a large amount of non-residential buildings lead to overestimation of population. The presented workflow has proven to be transferable and applicable on various study areas. In case of a flood event, the spatial representation of the flood extent and flood depths can be extracted by remote sensing technology as well (Zwenzner and Voigt, 2009). However, for the cities of Cologne and Dresden which have a broad and valuable database concerning flood-related information, the presented methodology could be tested and validated and proves applicability for areas with a less well developed database. Thereby a valuable 
contribution to the vulnerability assessment of flood prone areas as concerns exposure can be achieved. In the next step the integration of information on the susceptibility and the coping capacities of the exposed population, the built-up environment and critical infrastructures have to be accomplished. The application of quantitative and qualitative approaches can complement the method explored in this paper in a most promising way. Guidelines for comprehensive vulnerability assessment on the municipal level using remote sensing in combination with other approaches are currently being worked on in a project funded by the German Federal Office of Civil Protection and Disaster Assistance (BBK) and will be published end of 2009 (http://www.ehs.unu.edu/category:39?menu=82).

\section{ACKNOWLEDGEMENTS}

The authors would like to thank the cities of Cologne and Dresden for the provided digital surface models, the ATKIS data sets and the official digital building model and the City of Cologne for the reference data for the validation of the potentially affected population. We would also like to thank the German Federal Office of Civil Protection and Disaster Assistance (BBK) for funding this study and Christian Geiß and Maike Vollmer for their support.

\section{REFERENCES}

[1] Aubrecht, C., Steinnocher, K., Hollaus, M. and Wagner, W., "Integrating earth observation and GIScience for high resolution spatial and functional modeling of urban land use," Computers, Environment and Urban Systems 33(1), 15-25 (2009).

[2] Baatz, M. and Schäpe, A., "Multiresolution Segmentation: an optimization approach for high quality multi-scale image segmentation," Angewandte Geographische Informationsverarbeitung XII: Beiträge zum AGIT-Symposium Salzburg 2000, 12-23 (2000).

[3] Blaschke, T. and Strobl, J., "What's wrong with pixels? Some recent developments interfacing remote sensing and GIS," GIS, no. 6, 12-17 (2001).

[4] Brenner, C., "Dreidimensionale Gebäuderekonstruktion aus digitalen Oberflächenmodellen und Grundrissen," Dissertation, Universität Stuttgart (2000).

[5] Chen, K, "An approach to linking remotely sensed data and areal census data," International Journal of Remote Sensing 23(1), 37-48 (2002).

[6] Donnay, J.-P, Barnsley, M. J. and Longley, P. A., [Remote Sensing and Urban Analysis], Taylor and Francis, London \& New York, 3-18 (2001).

[7] www.dresden-online.de

[8] Esch, T., Thiel, M., Bock, M. and Dech, S., "Improvement of image segmentation accuracy based on multi-scale optimization procedure," IEEE Geoscience and Remote Sensing Letters 5(3), (2008).

[9] Federal Ministry of Justice (Bundesministerium der Justiz), Bevölkerungsstatistikgesetz (BevStatG) and

Bundesstatistikgesetz (BeStatG), http://bundesrecht.juris.de

[10] Federal Statistical Office Germany (Statistisches Bundesamt), Wiesbaden, https://www-

genesis.destatis.de/genesis/online/logon (2009).

[11] Hofmann, A. D., "An approach to 3D building model reconstruction from airborne laser scanning data using parameter space analysis and fusion of primitives," Dissertation, Technische Universität Dresden (2005).

[12] Jensen, J. R. and Cowen, D. C., "Remote Sensing of Urban/Suburban Infrastructure and Socio-Economic Attributes," Photogrammetric Engineering \& Remote Sensing 65, 611-622 (1999).

[13] Kressler, F. and Steinnocher, K., "Object-oriented analysis of image and LiDAR data and its potential for a dasymetric mapping application," Object-based Image Analysis: Spatial Concepts for Knowledge Driven Remote Sensing Applications, Springer-Verlag Berlin \& Heidelberg, 611-624 (2008).

[14] Liu, X, Clarke, K., Herold, M., "Populatin Density and Image Texture: A Comparison Study," Photogrammetric Engineering \& Remote Sensing 72, 187-196 (2006).

[15] Landeshauptstadt Dresden, Kommunale Statistikstelle, Statistischer Informationsdienst.

http://www.dresden.de/de/02/06/c_020_Einwohnerzahl.php

[16] Maktav, D., Erbek, F. S. and Jürgens, C., "Remote Sensing of urban areas," International Journal of Remote

Sensing, Vol.26, no.4 (2005). 
[17] Neubert, M., Herold, H. and Meinel, G., "Evaluation of remote sensing image segmentation quality - further results and concepts," 1st International Conference on Object-based Image Analysis (OBIA 2006) (2006).

[18] Neubert, M. and Herold, H., "Assessment of remote sensing image segmentation quality," GEOBIA 2008 - Pixels, Objects, Intelligence (2008).

[19] Rottensteiner, F. and Briese, Ch., "Automatic generation of building models from Lidar data and the integration of aerial images," ISPRS XXXIV (2003).

[20] Rottensteiner, F., Trinder, J, Clode, S., Kubik, K. and Lovell, B., "Building detection by Dempster-Shafer fusion of LiDAR data and multispectral aerial imagery," ICPR'04 (2004).

[21] Stadt Köln, "Hochwasserschutzkonzept Köln," (1996).

[22] Stadtentwässerungsbetriebe Köln, AöR, http://www.steb-koeln.de/steb_koeln.html

[23] Steinnocher, K., Petrini, F, Tötzer, T. and Weichselbaum, J., "Räumliche Disaggregation von sozio-ökonomischen Daten," Angewandte Geographische Informationsverarbeitung XVII-Beiträge zum AGIT-Symposium (2005).

[24] Sutton, P., Roberts, D., Elvidge, C., and Meij, H., "A Comparison of Nighttime Satellite Imagery and Population density for the Continental United States," Photogrammetric Engineering and Remote Sensing 63, 1303-1313 (1997). [25] Taubenböck, H., Roth, A. and Dech, S., "Linking structural urban characteristics derived from high resolution satellite data to population distribution," Urban and Regional Data Management, 35-45 (2007).

[26] Taubenböck, H. and Roth, A., "A transferable and stable object oriented classification approach in various urban areas and various high resolution sensors," 2007 Urban Remote Sensing Joint Event (2007).

[27] Taubenböck, H., Wurm, M., N. Setiadi, N. Gebert, A. Roth, G. Strunz, J. Birkmann \& S. Dech (2009): Integrating Remote Sensing and Social Science - The correlation of urban morphology with socioeconomic parameters. 2009 Urban Remote Sensing Joint Event (2009).

[28] United Nations, "World Urbanization Prospects. The 2007 Revision," New York, 244p. (2008).

[29] Weidner, U., "Building Extraction from Digital Elevation Models," Technical Report, 56p (1996).

[30] Wurm, M., Taubenböck, H., Roth, A., Dech, S., "Urban structuring using multisensoral remote sensing data - By the example of the German cities Cologne and Dresden," 2009 Urban Remote Sensing Joint Event (2009).

[31] WWF, "Hochwasser in Deutschland und Europa," Hintergrundinformation (2007).

[32] Zwenzner, H. and Voigt, S., "Improved estimation of flood parameters by combining space based SAR data with very high resolution digital elevation data," Hydrology and Earth System Sciences 13, 567-576 (2009). 